\title{
Heterogeneous Catalytic Oxidation by MFU-1: A Cobalt(II)-Containing Metal-Organic Framework
}

\author{
Markus Tonigold, Ying Lu, Björn Bredenkötter, Bernhard Rieger, Stefan Bahnmüller, \\ Julia Hitzbleck, Gerhard Langstein, and Dirk Volkmer*
}

Porous metal-organic frameworks (MOFs) are a rapidly emerging class of multifunctional hybrid materials that might be useful for diverse technical applications, such as gas or liquid adsorption and separation, molecular recognition, or catalysis. $^{[1]}$ Combining polycarboxylate ligands and (transition) metal ions, moderately robust MOFs can be prepared; 1,4-benzenedicarboxylate (bdc, terephthalic acid) and 4,4'biphenyldicarboxylate (bpdc) are often used as linkers. Highly porous non-interpenetrated frameworks, such as the well-known MOF-5 $\left(\left[\mathrm{Zn}_{4} \mathrm{O}(\mathrm{bdc})_{3}\right]\right)^{[2]}$ or IRMOF-9 $\left(\left[\mathrm{Zn}_{4} \mathrm{O}-\right.\right.$ $\left.\left.(\mathrm{bpdc})_{3}\right]\right)^{[3]}$ then form. These microporous MOFs generally show good thermal stabilities (decomposition occurs at $T>$ $350^{\circ} \mathrm{C}$ ). A fundamental disadvantage, however, is their low hydrolytic stability: Decomposition of the framework occurs rapidly when the gas or liquid phase contains a small amount of water, ${ }^{[4]}$ which imposes severe limitations on their usage in catalytic oxygenation reactions, in which water is a major reaction product. Preliminary attempts to use MOF-5 as a photocatalyst have been reported recently $;^{[5]}$ however, the fact that these frameworks contain Lewis acidic zinc(II) ions only imposes severe limitations on their use in redox catalytic applications in general.

Conceptually different approaches have been reported to circumvent the intrinsic disadvantages of MOF-5-type frameworks. Fischer et al. reported the gas-phase deposition of volatile organometallic complexes in the open cavities of MOF-5. Subsequent photolytic or reductive cleavage of the precursors led to catalytically active metal clusters $(\mathrm{Cu}, \mathrm{Pd}$, $\mathrm{Au})$ that are finely dispersed in the MOF-5 framework. ${ }^{[6]}$ Nguyen, Hupp et al. were among the first to present

[*] M. Tonigold, ${ }^{[+]}$Dr. Y. Lu, ${ }^{[+]}$Dr. B. Bredenkötter, Prof. D. Volkmer Institut für Anorganische Chemie II-Materialien und Katalyse Universität Ulm, Albert-Einstein-Allee 11, 89081 Ulm (Germany) Fax: (+ 49) 731-50-23039

E-mail: dirk.volkmer@uni-ulm.de

Homepage: http://www.uni-ulm.de/nawi/nawi-anorg2

Prof. B. Rieger

WACKER-Lehrstuhl für Makromolekulare Chemie

Technische Universität München

Lichtenbergstrasse 4, 85747 Garching (Germany)

Dr. S. Bahnmüller, Dr. J. Hitzbleck, Dr. G. Langstein

Bayer MaterialScience AG, BMS-CD-NB-NT

Gebäude B211, 51368 Leverkusen (Germany)

['] These authors contributed equally to this work. oxidations using a MOF catalyst. ${ }^{[7]}$ They used an enantiomerically pure manganese complex of a modified salen ligand as a building block to construct a three-dimensional porous framework. A distinct approach towards heterogeneous asymmetric catalysis based on a homochiral metal-organic framework was recently proposed by Lin et al. ${ }^{[8]}$ However, industrial oxidation or oxygenation reactions typically require very high turn-over numbers (TONs) and frequencies (TOFs), which have not been achieved to date by current MOF catalysts.

To produce thermally and hydrolytically stable redoxactive MOFs, our initial efforts focused on the isostructural replacement of a single zinc ion by an open-shell transition metal ion $\mathrm{M}$ within the tetranuclear $\left\{\mathrm{Zn}_{4} \mathrm{O}\right\}$ coordination unit of MOF-5. However, all attempts in this direction led to heteronuclear MOFs containing trinuclear coordination units (for example, $\left[\mathrm{MZn}_{2}(\mathrm{bpdc})_{3}(\mathrm{dmf})_{2}\right], \mathrm{M}=\mathrm{Co}^{\mathrm{II}}, \mathrm{Ni}^{\mathrm{II}}, \mathrm{Cd}^{\mathrm{II}}$ ), which are structurally different from MOF-5. ${ }^{[9]}$ A search of the CSD database, however, led to the tetranuclear complex $\left[\mathrm{Co}_{4}{ }_{4} \mathrm{O}(3,5-\mathrm{dmpz})_{6}\right] \quad(3,5-\mathrm{dmpz}=3,5$-dimethylpyrazolate $),{ }^{[10]}$ which is a structural analogue of basic zinc acetate, $\left[\mathrm{Zn}_{4} \mathrm{O}\right.$ $\left.(\mathrm{OAc})_{6}\right]$, the prototypic secondary building unit of MOF-5 (Figure 1). Thus, reacting the ligand 1,4-bis[(3,5-dimethyl)pyrazol-4-yl]benzene $\left(\mathrm{H}_{2} \mathrm{bdpb}\right)^{[11]}$ with suitable cobalt(II) salts under solvothermal conditions led to formation of a series of novel cobalt(II)-based MOF compounds, ${ }^{[12]}$ one of which, $\left[\mathrm{Co}_{4}^{\mathrm{II}} \mathrm{O}(\mathrm{bdpb})_{3}\right](\mathrm{MFU}-1),{ }^{[13]}$ is described herein.

Single crystals of MFU-1 were grown under solvothermal conditions from solutions of the ligand $\mathrm{H}_{2} \mathrm{bdpb}$ and cobalt(II) chloride in $\mathrm{DMF}$ at $120^{\circ} \mathrm{C}$ (see the Supporting Information). For a more efficient bulk synthesis of the phase-pure compound, we employed a microwave system, which reduced the reaction time from several days to a few minutes. X-ray powder diffraction studies (Supporting Information, Figure S2) showed that microcrystals obtained from the microwave-assisted synthesis are structurally identical to those obtained from solvothermal synthesis, but they are significantly smaller and more uniform in size (Supporting Information, Figures S3, S4). ${ }^{[16]}$

MFU-1 crystallizes in space group $P \overline{4} 3 m$ with $a=$ $15.963 \AA .{ }^{[17]}$ The bdpb ligands and $\left\{\mathrm{Co}_{4} \mathrm{O}\right\}$ units are linked into a non-interpenetrated network (Figure 2) of low density $\left(\rho_{\text {calcd }}=0.43 \mathrm{~g} \mathrm{~cm}^{-3}\right)$. The structure of MFU-1 is similar to MOF-5, which has a $\mathrm{CaB}_{6}$-type framework topology. The MFU-1 network encloses octahedral $\left\{\mathrm{Co}_{4} \mathrm{O}(\mathrm{dmpz})_{6}\right\}$ nodes that are reminiscent of the $\left\{\mathrm{Zn}_{4} \mathrm{O}\left(\mathrm{CO}_{2}\right)_{6}\right\}$ secondary building units of MOF-5. Phenylene rings constituting the edges of the cubic $\mathrm{CaB}_{6}$ network. The framework has three-dimensional intersecting channels that encompass almost spherical voids 
a)

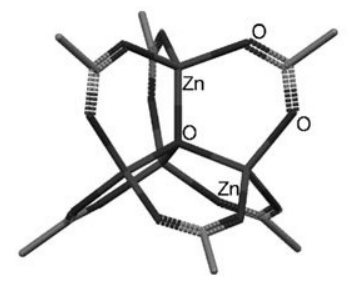<smiles>CC(=O)Oc1cccc2ccccc12</smiles>

b)
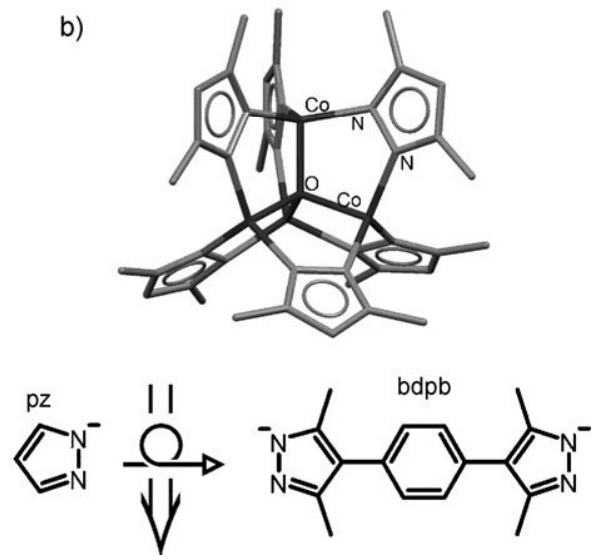

Figure 1. a) Replacement of acetate from basic zinc acetate, $\left[\mathrm{Zn}_{4} \mathrm{O}\right.$ $(\mathrm{OAc})_{6}{ }_{6}{ }^{[14]}$ with 1,4-benzenedicarboxylate (bdc) leads to MOF-5, $\left[\mathrm{Zn}_{4} \mathrm{O}\right.$ (bdc) ${ }_{3} .^{\left[{ }^{[2]}\right.}$ b) Similar to the case in (a), redox-active MFU-1 can be derived from $\left[\mathrm{Co}_{4}{ }_{4} \mathrm{O}(3,5-\mathrm{dmpz})_{6}\right]^{[15]}$ by replacing dimethylpyrazolate (dmpz) ligands with bdpb.

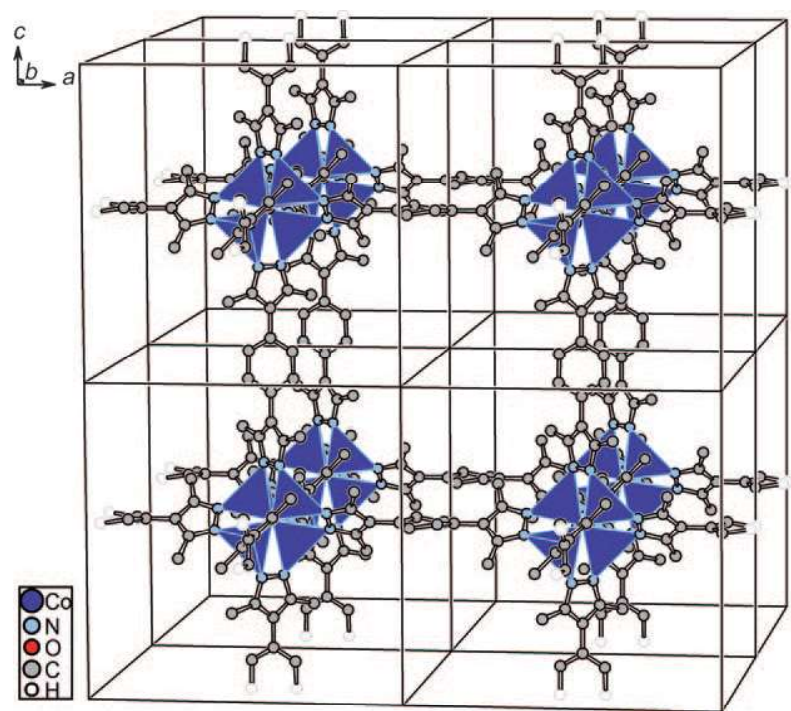

Figure 2. Crystal packing of MFU-1. $\left\{\mathrm{CoON}_{3}\right\}$ coordination units are shown as blue polyhedrons. Phenylene moieties of the bridging bdpb ligands occupy two alternative positions with equal probability; only one position is given. Hydrogen atoms are omitted for clarity. with a volume of about $3100 \AA^{3}$ each (corresponding to an equivalent diameter of $18.1 \AA$; Figure 2). A structurally related MOF network constructed from $\mu_{4}$-oxo-bridged tetrazinc units and 3,3',5,5'-tetramethyl-4,4'-bipyrazolate linkers has been reported recently. ${ }^{[18]}$

The thermal stability of MFU-1 was investigated by thermogravimetric (TG) analysis and variable-temperature $\mathrm{X}$-ray powder diffraction (VTXRPD). The TG analysis shows a loss of occluded solvent molecules in the temperature range of $75-225^{\circ} \mathrm{C}$ to yield the solvent-free crystal form (weight loss: $11.9 \%$; expected: $12.3 \%$ for complete loss of DMF from MFU-12DMF). No further weight loss occurs below $340^{\circ} \mathrm{C}$; $\mathrm{H}_{2}$ bdpb molecules are released in the temperature range of $340-600^{\circ} \mathrm{C}$. Upon suspending MFU-1 in dichloromethane for $24 \mathrm{~h}$ followed by drying in vacuum, the initially occluded DMF molecules are removed completely, which is indicated by a residual weight loss of $2.9 \%$ in the temperature range 30 $195^{\circ} \mathrm{C}$, with no further weight loss occurring below $340^{\circ} \mathrm{C}$. The VTXRPD patterns indicate that the MFU-1 framework is stable up to $270^{\circ} \mathrm{C}$ (Supporting Information, Figures S5S7).

MFU-1 has permanent porosity, which was confirmed by an argon gas sorption experiment. Prior to measurement, the sample was refluxed several times in dichloromethane to exchange the DMF molecules with the more-volatile solvent. The sorption isotherm of MFU-1 obtained with argon gas reveals a type I sorption behavior, which is characteristic of microporous solids (Supporting Information, Figure S8). The adsorption data were analyzed to give BET surface areas of 1525 for MFU-1 obtained by solvothermal synthesis and $1485 \mathrm{~m}^{2} \mathrm{~g}^{-1}$ for MFU-1 from microwave synthesis. ${ }^{[19]}$ The values of micropore surface area and volume for MFU-1 are relatively high in comparison to those of microporous zeolites and aluminophosphates, and similar to the lower values reported for MOF-5 (600-3400 $\left.\mathrm{m}^{2} \mathrm{~g}^{-1}\right)^{[3,20]}$ and similar compounds. In accordance to previous reports, we ascribe the reduced surface area in MFU-1 to a partial filling of the microporous channels with non-volatile unidentified molecular species ${ }^{[21]}$ and to Ostwald ripening of the pore systems. ${ }^{[22]}$

The UV/Vis diffuse reflectance spectrum (Supporting Information, Figure S9) of MFU-1 shows several absorption bands in the UV region, which correspond to intraligand $\mathrm{n} \rightarrow$ $\pi^{*}$ and $\pi \rightarrow \pi^{*}$ transitions (Supporting Information, Figure S10). In the visible region, MFU-1 has a broad absorption band centered at $610 \mathrm{~nm}\left(16393 \mathrm{~cm}^{-1}\right)$, which can be assigned to the spin-allowed d-d transition ${ }^{4} \mathrm{~A}_{2}(\mathrm{~F}) \rightarrow{ }^{4} \mathrm{~T}_{2}(\mathrm{~F})$ of tetrahedral cobalt(II) ions. ${ }^{[23]}$

The hydrolytic stability of MFU-1 was investigated by several experiments. Microcrystals of MFU-1 were placed for $96 \mathrm{~h}$ into ethanol, which is used as a test protic solvent, upon which no discernible changes occurred in the UV/Vis spectra or the XRPD patterns (Supporting Information, Figure S11). This characteristic is unaffected by increasing amounts of water added to the crystal suspensions (up to $30 \mathrm{vol} \% \mathrm{H}_{2} \mathrm{O}$ ). In long-term experiments, we could not find any signs of degradation when MFU-1 crystals were stored at ambient conditions for more than six months, which is in sharp contrast to the moisture sensitivity of many zinc terephthalate MOFs. 
As a test reaction for catalytic activity, the liquid-phase oxidation of cyclohexene in the presence of MFU-1 was examined using tert-butyl hydroperoxide as oxidant. In contrast to numerous reports on the oxidation, catalytic or otherwise, of cyclohexane by cobalt(II) complexes, ${ }^{[24]}$ the corresponding transformation of cyclohexene has been explored to lesser extent. ${ }^{[25]}$ The experimental data demonstrate that oxidation of cyclohexene is fast, and several turnovers are possible in the presence of MFU-1 (Figure $3 \mathrm{a}$ ), whereas the reaction occurring in absence of catalyst under
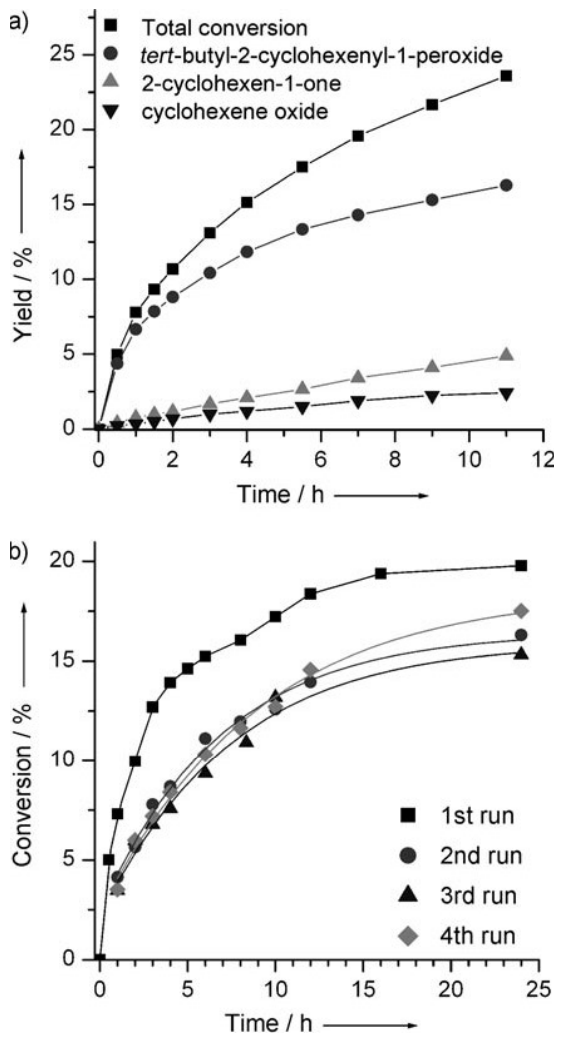

Figure 3. a) Yield versus time curves for cyclohexene oxidation with MFU-1 as catalyst. b) Cyclohexene conversion versus time curves for catalytic oxidation using MFU-1 in four subsequent runs. Reaction conditions: cyclohexene (16 mmol), $\mathrm{tBuOOH}(8 \mathrm{mmol}), 1,2,4$-trichlorobenzene ( $2 \mathrm{mmol}$; as internal standard), MFU-1 $(0.095 \mathrm{mmol}$, based on cobalt), $T=70^{\circ} \mathrm{C}$.

the same conditions is almost negligible (ca. $1 \%$ conversion after $12 \mathrm{~h}$ ). The maximum substrate conversion achieved after $22 \mathrm{~h}$ was $27.5 \%$, and the main reaction products are tert-butyl2-cyclohexenyl-1-peroxide, followed by 2-cyclohexen-1-one and cyclohexene oxide, as revealed by combined gas chromatographic and mass spectrometric product analysis. MFU-1 has an exceptionally high selectivity toward allylic substitution, that is, formation of tert-butyl-2-cyclohexenyl-1-peroxide (ca. 66\%), which is a typical reaction for the homogeneous catalysis with cobalt(II) complexes of bis(salicylamide) ligands when alkyl hydroperoxides are used as the oxidant. ${ }^{[25]}$ A similar catalytic conversion for the oxidation of cyclohexene was recently achieved by immobilization of lowmolecular-weight cobalt complexes to alumina supports. ${ }^{[26]}$
MFU-1 can be almost completely recovered from the reaction vessel after a catalytic test run. During the reaction with tertbutyl hydroperoxide, microcrystals of MFU-1 undergo a slow color change from blue to green, but the crystal morphology is retained (Supporting Information, Figures S9, S12). X-ray powder diffraction data of the recovered catalyst gave no signs of decomposition (Supporting Information, Figure S13). Employing MFU-1 in several catalytic runs leads to a loss of catalytic activity after the first run (Figure $3 \mathrm{~b}$ ), but no further loss in catalytic activity is observed in subsequent runs. The BET surface area of MFU-1 decreases from $1485 \mathrm{~m}^{2} \mathrm{~g}^{-1}$ to $1018 \mathrm{~m}^{2} \mathrm{~g}^{-1}$ after the first run. We ascribe the partial loss of activity and the reduction of surface area to the formation of polar reaction products during catalysis that might block active sites and adsorption sites in the crystal lattice.

To confirm the heterogeneous nature of the catalytic reaction, we performed hot-filtration experiments: the solid catalyst was removed from hot solution by filtration two hours after initiating the catalytic test run. The reaction of the filtrate was then monitored for another $10 \mathrm{~h}$; no significant catalytic conversion was observed, indicating that cobalt ions leaching from the catalyst (if any) are not responsible for the observed activity (Figure 4). The filtrate was also analyzed by atomic absorption spectroscopy, which indicated a very low concentration of free cobalt(II) ions in the filtrate: Less than $1.1 \times 10^{-3} \%$ of the cobalt ions in MFU- 1 are leached out into the reaction solution.

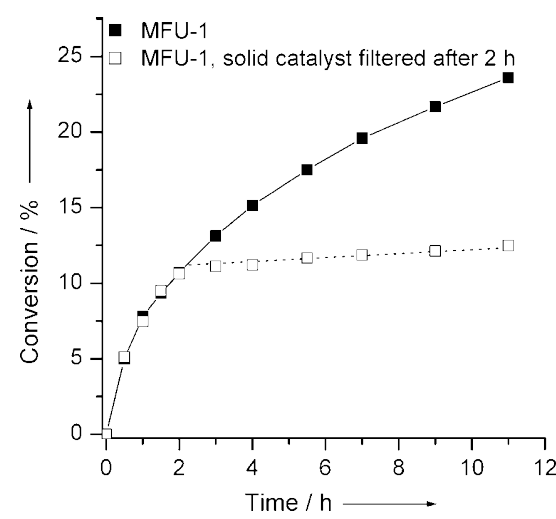

Figure 4. Conversion versus time curves for cyclohexene oxidation with

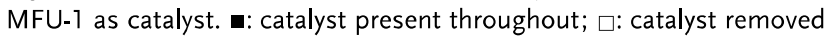
from the suspension after $2 \mathrm{~h}$.

Evidence that catalysis occurs inside the pores is a nontrivial task owing to the very large aperture of the MFU-1 channels. To investigate whether the catalytic transformation proceeds inside the pores or on the external crystal surface, the effect of crystal size on the catalytic activity of MFU-1 was evaluated. On average, crystal specimens of MFU-1 obtained from microwave synthesis have an external surface area that is approximately eight times higher than those from solvothermal synthesis (Supporting Information, Figure S3, S4). Assuming that the reaction proceeds at the outer crystal surface only, an eight-fold increase in catalytic activity should then be observed for crystals obtained from microwave synthesis when employing equal amounts of MFU-1 in both 
test reactions under identical reaction conditions. On the other hand, mass-transfer limitations can drastically reduce the effectiveness of the catalyst, especially when the reaction occurs inside narrow pores or channels. Both external mass transfer (rate of transport to the outer surface) and internal mass transfer (rate of intracrystalline transport) increase in importance with increasing particle size. ${ }^{[27,28]}$ It is often observed in zeolite catalysis that the internal mass transfer is the rate-determining step. ${ }^{[28]}$ Therefore, initial reaction rates with respect to catalyst loading were determined for crystals obtained from solvothermal and microwave synthesis (Figure 5).

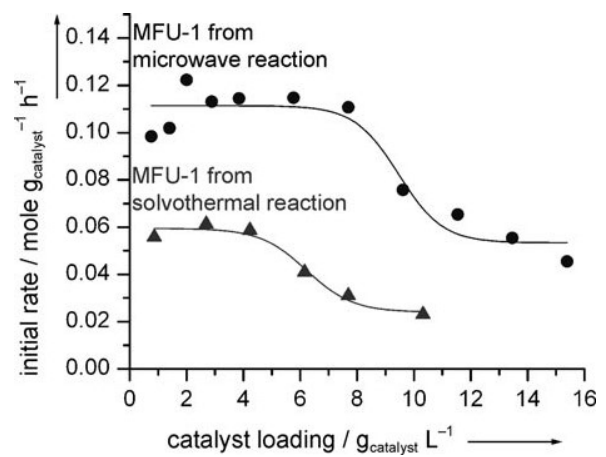

Figure 5. Initial rates for the production of tert-butyl-2-cyclohexenyl-1peroxide versus catalyst loading.

Constant activity is observed with low catalyst loadings for both crystal sizes, whereas with higher loadings, the activity is diminished owing to external mass transfer (film diffusion). In the region of low catalyst loading, the initial reaction rates differ by a factor of two when using MFU-1 obtained from microwave and solvothermal synthesis. As this factor is by far less than a factor of about eight expected for the catalytic reaction taking place at the external crystal surface exclusively, we ascribe the observed size dependency of catalytic activity to internal mass transfer (pore diffusion) limitations.

This interpretation is further supported by inhibition studies in which MFU-1 sample were treated with cyanide or fluoride ions prior to catalytic tests. These investigations show that the catalytic activity is almost completely unaffected by treating catalyst particles with such strongly coordinating ligands. As the UV/Vis absorption spectrum of the catalyst does not change upon $\mathrm{CN}^{-} / \mathrm{F}^{-}$treatment, a coordination of these to intracrystalline cobalt(II) centers (i.e. $\left\{\mathrm{Co}_{4}^{\mathrm{II}}{ }_{4} \mathrm{O}\right\}$ building units) can thus be ruled out. Catalyst poisoning and inhibition might still occur at defects on the external surface of MFU-1; such a process does not however affect catalytic activity (Supporting Information, Figure S14).

To further investigate whether the oxidation reaction takes place inside the pores of MFU-1, we performed comparative catalytic test reactions by replacing tert-butyl hydroperoxide with the sterically more demanding triphenylmethyl hydroperoxide molecule $\left(\mathrm{Ph}_{3} \mathrm{COOH}\right)$. When this more bulky oxidant is used, the rate of the catalytic test reaction drops significantly relative to the reaction employing tert-butyl hydroperoxide. Moreover, in contrast to framework activation by $t \mathrm{BuOOH}$, no color change of MFU-1 appears in the presence of $\mathrm{Ph}_{3} \mathrm{COOH}$ (Supporting Information, Figures S15 and S16). These results indicate that activation of the catalyst and the reaction is confined to the particle surface in the case of $\mathrm{Ph}_{3} \mathrm{COOH}$, whereas the reaction takes place inside the pores of MFU-1 employing $t \mathrm{BuOOH}$, which can freely diffuse inside the framework.

All our results from catalytic test reactions on MFU-1 obtained to date clearly point to a heterogeneous catalytic reaction that takes place inside the pores of the MOF lattice. To our knowledge, MFU-1 is the first example for which this feature has been unequivocally demonstrated. The fact that tert-butyl-2-cyclohexenyl-1-peroxide is the main reaction product suggests a reaction pathway in which freely diffusing peroxy radicals are generated by reductive cleavage of tertbutyl hydroperoxo ligands coordinating to cobalt(III) metal centers $^{[24]}$ (see the Supporting Information). UV/Vis and XPS measurements provide further evidence for the presence of cobalt(III) after long catalytic runs, whereas only cobalt(II) is present initially (Supporting Information, Figures S9, S17). The byproduct, 2-cyclohexe-1-one, is most likely formed by thermal decomposition of the main product, tert-butyl-2cyclohexenyl-1-peroxide.

In summary, we have prepared a novel redox-active MOF, which is structurally analogous to the zinc-containing and thus redox-inactive MOF-5. In contrast to many MOFs reported previously, the compound described herein has excellent stability against hydrolytic decomposition in the presence of water or similar protic solvents. This feature is mainly due to the use of N-heterocyclic ligands, which form thermodynamically stable complexes with cobalt(II) ions. Moreover, we have successfully demonstrated that catalytic oxidation reactions employing redox-active MOFs are feasible. Catalytic turnover was achieved, and the catalyst is easily recovered by filtration from the heterogeneous reaction mixtures. Corma et al. ${ }^{[29]}$ have recently described the catalytic oxidation of tetralin with molecular oxygen using cobalt(II)containing MOF ZIF-9 ${ }^{[30]}$ as catalyst. They achieved $23 \%$ conversion (with tetralone as the main product) after $30 \mathrm{~h}$. An induction period of about $10 \mathrm{~h}$ was found in which no tetralin conversion was observed. Similar to MFU-1, the catalyst ZIF9 shows no metal leaching; however, the influence of active metal sites exposed on the external particle surface were not reported. As the molecular dimensions of tetralin are $0.46 \times$ $0.65 \mathrm{~nm}$, whereas the pore aperture in ZIF-9 is only about $0.30 \mathrm{~nm},{ }^{[31]}$ the intrapore diffusion of tetralin in ZIF-9 should be strongly hindered, which might suggest that the catalytic oxidation is primarily confined to the particle surface, which is in contrast with MFU-1. We hope that investigations on MFU-1 will stimulate further research on the development of catalytically active MOFs. We are currently screening catalytic activities of MFU-1 in different reactions by combining a broad variety of different oxidants and substrates. 
[1] For recent reviews on different aspects of MOF applications, see a) M. Eddaoudi, D. B. Moler, H. Li, B. Chen, T. M. Reineke, M. O'Keeffe, O. M. Yaghi, Acc. Chem. Res. 2001,34,319-330; b) G. Férey, C. Mellot-Draznieks, C. Serre, F. Millange, Acc. Chem. Res. 2005, 38, 217-225; c) U. Müller, M. Schubert, F. Teich, H. Puetter, K. Schierle-Arndt, J. Pastré, J. Mater. Chem. 2006, 16, 626-636.

[2] H. Li, M. Eddaoudi, M. O'Keeffe, O. M. Yaghi, Nature 1999, 402, $276-279$.

[3] M. Eddaoudi, J. Kim, N. Rosi, D. Vodak, J. Wachter, M. O'Keefe, O. M. Yaghi, Science 2002, 295, 469-472.

[4] J. A. Greathouse, M. D. Allendorf, J. Am. Chem. Soc. 2006, 128, 10678-10679; Erratum: J. A. Greathouse, M. D. Allendorf, $J$. Am. Chem. Soc. 2006, 128, 13312.

[5] a) F. X. Llabrés i Xamena, A. Corma, H. Garcia, J. Phys. Chem. C 2007, 111, 80-85; b) J. Gascon, M. D. Hernández-Alonso, A. R. Almeida, G. P. M. van Klink, F. Kapteijn, G. Mul, ChemSusChem 2008, 1, 981-983.

[6] S. Hermes, M.-K. Schröter, R. Schmid, L. Khodeir, M. Muhler, A. Tissler, R. W. Fischer, R. A. Fischer, Angew. Chem. 2005, 117, 6394-6397; Angew. Chem. Int. Ed. 2005, 44, 6237-6241.

[7] S.-H. Cho, B. Ma, S. T. Nguyen, J. T. Hupp, T. E. AlbrechtSchmitt, Chem. Commun. 2006, 2563-2565.

[8] C.-D. Wu, W. Lin, Angew. Chem. 2007, 119, 1093-1096; Angew. Chem. Int. Ed. 2007, 46, 1075-1078.

[9] Y. Wang, B. Bredenkötter, B. Rieger, D. Volkmer, Dalton Trans. 2007, 689-696.

[10] $\left(\mu_{4}\right.$-Oxo)hexakis $\left(\mu-3,5\right.$-dimethylpyrazolato- $\left.N, N^{\prime}\right)$ tetracobalt(II) (CSD ID: LESNUS): M. K. Ehlert, S. J. Rettig, A. Storr, R. C. Thompson, J. Trotter, Acta Crystallogr. Sect. C 1994, 50, $1023-$ 1026.

[11] F. Ramirez, S. B. Bhatia, A. V. Patwardhan, C. P. Smith, J. Org. Chem. 1967, 32, 3547-3553.

[12] German Patent and Trademark Office, S. Bahnmüller, G. Langstein, J. Hitzbleck, D. Volkmer, Y. Lu, M. Tonigold, DE102008027218A1, 2009.

[13] MFU is the acronym for Metal-Organic Framework Ulm University.

[14] Hexakis $\left(\mu_{2}\right.$-acetato-O,O $\left.\mathrm{O}^{\prime}\right)$ - $\left(\mu_{4}\right.$-oxo)-tetrazinc

(CSD ID : ZNOXAC): H. Kovama, Y. Saito, Bull. Chem. Soc. Jpn. 1954, 27, $112-114$

[15] Catena[bis( $\mu_{2}$-pyrazolato)cobalt(II)] (CSD ID: AQOPEB): N Masciocchi, G. A. Ardizzoia, S. Brenna, G. LaMonica, A. Maspero, S. Galli, A. Sironi, Inorg. Chem. 2002, 41, 6080-6089.

[16] Similar results were recently reported on the microwave-assisted synthesis for a range of zinc terephthalate based MOFs: Z. Ni, R. I. Masel, J. Am. Chem. Soc. 2006, 128, 12394-12395.

[17] Crystal data for MFU-1: $\left[\mathrm{Co}_{4} \mathrm{O}\left(\mathrm{C}_{16} \mathrm{H}_{16} \mathrm{~N}_{4}\right)_{3}\right]_{n}^{\infty}, \mathrm{C}_{48} \mathrm{H}_{48} \mathrm{~N}_{12} \mathrm{OCo}_{4}$, $M_{\mathrm{r}}=1044.70$, cubic, space group $P \overline{4} 3 m, a=15.963(2) \AA, V=$ $4067.9(8) \AA^{3}, Z=1, \rho_{\text {calcd }}=0.426 \mathrm{~g} \mathrm{~cm}^{-3}$. In the chosen achiral space group, the phenylene moiety of the bridging bdpb ligand occupies two alternative positions, each with $50 \%$ probability. Crystals suitable for single crystal $\mathrm{X}$-ray structure analysis of this compound are notoriously hard to obtain, because the crystal specimens are small $(<50 \mu \mathrm{m})$ and show a marked tendency of (inversion) twinning. To remove the occluded DMF solvent molecules, we refluxed a suspension of crystals several times with chloroform and kept the crystals for at least $12 \mathrm{~h}$ under high vacuum $\left(p<10^{-4} \mathrm{mbar}\right)$. The crystallographic data from six independent measurements all showed a large residual electron density in the void regions of the crystal lattice, which we could not refine any further. This electron density could be due to residual disordered solvent molecules, or it might result from crystal twinning.

[18] L. Hou, Y.-Y. Lin, X.-M. Chen, Inorg. Chem. 2008, 47, 13461351.

[19] a) T. Düren, F. Millange, G. Férey, K. S. Walton, R. Q. Snurr, J. Phys. Chem. C 2007, 111, 15350-15356; b) K. S. Walton, R. Q. Snurr, J. Am. Chem. Soc. 2007, 129, 1578-1585.

[20] The reported surface areas for MOF-5 substantially vary; see, for example: a) B. Panella, M. Hirscher, Adv. Mater. 2005, 17, $538-$ 541; b) Y. Li, R. T. Yang, J. Am. Chem. Soc. 2006, 128, 726-727; c) Y. Li, R. T. Yang, J. Am. Chem. Soc. 2006, 128, 8136-8137; d) B. Panella, M. Hirscher, H. Pütter, U. Müller, Adv. Funct. Mater. 2006, 16, 520-524; e) L. Huang, H. Wang, J. Chen, Z. Wang, J. Sun, D. Zhao, Y. Yan, Microporous Mesoporous Mater. 2003, 58, 105-114.

[21] J. Hafizovic, M. Bjørgen, U. Olsbye, P. D. C. Dietzel, S. Bordiga, C. Prestipino, C. Lamberti, K. P. Lillerud, J. Am. Chem. Soc. 2007, 129, 3612-3620.

[22] C.-S. Tsao, M.-S. Yu, T.-Y. Chung, H.-C. Wu, C.-Y. Wang, K.-S. Chang, H.-L. Chen, J. Am. Chem. Soc. 2007, 129, 15997-16004.

[23] a) A. B. P. Lever, Inorganic Electronic Spectroscopy, Elsevier, Amsterdam, 1968, chap. 9, p. 323; b) L. Poul, N. Jouini, F. Fiévet, Chem. Mater. 2000, 12, 3123-3132.

[24] a) F. A. Chavez, J. M. Rowland, M. M. Olmstead, P. K. Mascharak, J. Am. Chem. Soc. 1998, 120, 9015-9027; b) F. A. Chavez, J. A. Briones, M. M. Olmstead, P. K. Mascharak, Inorg. Chem. 1999, 38, 1603-1608; c) L. Saussine, E. Brazi, A. Robine, H. Mimoun, J. Fischer, R. Weiss, J. Am. Chem. Soc. 1985, 107, $3534-3540$.

[25] a) J. D. Koola, J. K. Kochi, J. Org. Chem. 1987, 52, 4545-4553; b) M. S. Kharasch, A. J. Fono, J. Org. Chem. 1959, 24, 72-78.

[26] M. Salavati-Niasari, M. Hassani-Kabutarkhani, F. Davar, Catal. Commun. 2006, 7, 955-962.

[27] H. S. Fogler, Elements of Chemical Reaction Engineering, Prentice-Hall, New Jersey, 1986.

[28] a) M. Al-Sabawi, J. A. Atias, H. de Lasa, Ind. Eng. Chem. Res. 2006, 45, 1583-1593; b) G. Tonetto, J. A. Atias, H. de Lasa, Appl. Catal. A 2004, 270, 9-25; c) M. A. Camblor, A. Corma, F. Martinez, F. A. Moccoli, Appl. Catal. 1989, 55, 65-74; d) J. Maselli, A. Peters, Catal. Rev. Sci. Eng. 1984, 26, 525-559; e) K. Rajagopalan, A. W. Peters, G. C. Edwards, Appl. Catal. 1986, 12, 69-80;f) C. Ercan, F. M. Dautzenberg, C. Y. Yeh, H. E. Barner, Ind. Eng. Chem. Res. 1998, 37, 1724-1728; g) A. Chantong, F. E. Massoth, AIChE J. 1983, 29, 725-731.

[29] F. X. Llabrés i Xamena, O. Casanova, R. G. Tailleur, H. Garcia, A. Corma, J. Catal. 2008, 255, 220-227.

[30] K. S. Park, Z. Ni, A. P. Cote, J. Y. Choi, R. D. Huang, F. J. UribeRomo, H. K. Chae, M. O'Keeffe, O. M. Yaghi, Proc. Natl. Acad. Sci. USA 2006, 103, 10186-10191.

[31] The van der Waals radius of carbon $(0.17 \mathrm{~nm})$ was used to calculate the width of the apertures: A. Bondi, J. Phys. Chem. 1964, $68,441-451$. 